\title{
Adherence to highly active antiretroviral therapy and associated factors among children at the University of Gondar Hospital and Gondar Poly Clinic, Northwest Ethiopia: a cross-sectional institutional based study
}

\author{
Berihun Assefa Dachew ${ }^{1 *}$, Tadis Brhane Tesfahunegn ${ }^{2^{*}}$ and Anteneh Messele Birhanu ${ }^{3^{*}}$
}

\begin{abstract}
Background: The efficacy of antiretroviral therapy (ART) in suppressing viral replication and delaying the progress of the acquired immunodeficiency syndrome (AIDS) is related to optimal adherence. Adherence is a challenge in all HIV infected people on ART. It is especially a concern in children because of factors relating to children such as age, disclosure status of HIV sero status, and understanding of the medication. This study assessed the level of adherence to highly active antiretroviral therapy and its associated factors among children in Gondar University Hospital and Gondar Poly Clinic, Northwest Ethiopia.
\end{abstract}

Methods: Institutionally based cross-sectional study design was conducted from January-to March 2012. Simple random sampling technique was used to select study participants and a total of 342 study subjects were included in the study. Bivariate and multivariate logistic regressions were performed to identify associated factors with adherence to highly active antiretroviral therapy. Odds ratios with 95\% confidence interval were computed to determine the level of significance.

Results: The overall ART adherence among children was found to be $90.4 \%$. Age of the child [AOR $=0.37$ ( $95 \%$ Cl: 0.31, 0.46)], disclosure of the child's HIV status to the child [AOR $=0.27$ (95\% Cl: $0.24,0.32)]$, and knowledge of caregivers about ART medication $[\mathrm{AOR}=4.7(95 \% \mathrm{Cl}(3.7,5.6)]$, were independently associated with adherence.

Conclusion: Adherence rate to ART was found to be high. Disclosure of the child's HIV sero status to the child, the age of the child and the knowledge of the caregivers towards ART were factors associated with adherence.

Keywords: Adherence, Antiretroviral therapy, Children

\section{Background}

Acquired immunodeficiency syndrome (AIDS) is a major threat to the world's population and it is the most devastating disease humankind has ever seen. In 2010, there were an estimated 33.3 million people living with HIV/AIDS in the world, of which more than $90 \%$ live in developing countries.

\footnotetext{
*Correspondence: berihunassefa21@gmail.com; taddis2007@gmail.com; antenehmessele33@gmail.com

'University of Gondar, College of medicine and Health science, Institute of public health, Department of Epidemiology and Bio-statistics, P.O. Box: 196, Gondar, Ethiopia

${ }^{2}$ Department of Nursing, Axum University, P.O. Box: 1010, Axum, Ethiopia ${ }^{3}$ Department of Nursing, University of Gondar, College of Medicine and Health Science, P.O. Box: 196, Gondar, Ethiopia
}

Among these, children less than 15 years of age account for around 2.5 million. Africa alone contains two-thirds of the world's total prevalence [1]. Sub-Saharan Africa is more heavily affected by HIV/AIDS than any other region of the world [2]. Of all deaths due to AIDS in the world, 1.6 million occurred in Sub-Saharan Africa [3]. In Ethiopia, there were about 1.2 million people living with HIV in the year 2010 alone and the overall prevalence is $2.3 \%$ [4]. A total of 258,264 people living with HIV/AIDS are in need of ART, and $6.1 \%$ are children [5]. Free antiretroviral treatment (ART) service was launched in Ethiopia in January 2005 and hospitals began providing free antiretroviral drugs in March 2005. The government focused on accelerated access to ART

\section{Biomed Central}

(C) 2014 Dachew et al.; licensee BioMed Central Ltd. This is an Open Access article distributed under the terms of the Creative Commons Attribution License (http://creativecommons.org/licenses/by/2.0), which permits unrestricted use, distribution, and reproduction in any medium, provided the original work is properly credited. The Creative Commons Public Domain Dedication waiver (http://creativecommons.org/publicdomain/zero/1.0/) applies to the data made available in this article, unless otherwise stated. 
in June 2006. This accelerated access, especially in health centers, was not accompanied by an equally rapid rise in ART uptake as expected [6]. Although resources are expanding in the overall HIV situation, preventing and treating pediatric HIV infection in resource-limited settings remains extremely challenging [7].

Despite the fact that the treatments are not a cure and present new challenges with respect to side-effects and drug resistance, these treatments have dramatically reduced rates of mortality and morbidity, improved the quality of life of people with HIV/AIDS, and given encouragement to the communities [8]. However, the efficacy of antiretroviral therapy in suppressing viral replication and delaying the progress of AIDS is related to optimal adherence.

Inadequate adherence increases the risk of drug resistance and treatment failure. Therefore, optimum adherence is highly essential for sustainable success to highly active antiretroviral treatment (HAART) [9]. Taking greater than $95 \%$ of prescribed doses is recommended for optimal virologic suppression and to minimize the rate of treatment failure $[10,11]$. Virologic failure rate of greater than $50 \%$ is associated with less than 95\% adherence rate [11].

Though adherence is a challenge in all HIV infected people who are on ART, it is a special concern in children. The lack of pediatric formulations, poor palatability, high pill burden or liquid volume, frequent dosing requirements, dietary restrictions and side-effects may hinder the regular intake of required medications [10]. In addition, poor understanding of the need to take the medication by the parents, and parents who may not wish to disclose the HIV status to the child or to others involved in their child's care are some of the challenges of adherence to HAART in resource limited settings like Ethiopia [10]. Furthermore, the successful treatment of a child requires the commitment and involvement of a responsible caregiver. This may be particularly complicated if the family unit is disrupted as a consequence of adverse health or economic conditions [12] though the burden of numerous pills is expected to be decreased after the initiation of fixed dose combination [12]. Therefore, evaluating the HAART adherence among children living with HIV can provide significant information for policy makers and organizations working in this area to develop appropriate interventions for ART adherence among children. This will achieve better health outcomes and prevent the emergence of HIV drug resistance strains. This study was aimed at assessing the level of adherence and associated factors to HAART in order to improve sustainable outcomes of HAART among children.

\section{Methods}

\section{Study design}

Institutionally based, cross-sectional quantitative study design was conducted at Gondar University Hospital and Gondar Poly Clinic Pediatrics ART Unit.

\section{Study area and period}

The study was conducted from January to March 2012 in Gondar University Hospital and Gondar poly Clinic pediatrics ART Unit.

\section{Source and study population}

All children who were taking HAART and on ART follow up with Gondar University Hospital and Gondar Poly Clinic.

\section{Inclusion criteria}

Children aged 2 months to 15 years receiving HAART for at least 2 months were included in the study. Approximately 742 children fulfilled the inclusion criteria.

\section{Sampling procedure}

Sample size was calculated by using a single population proportion formula with the assumption of $95 \%$ level of confidence, $5 \%$ marginal error, taking the proportion of adherence rate $80.9 \%$ [13] considering $10 \%$ non response rate. Using this assumption, out of 742 children on ART, a total 342 children were included in the study using simple random sampling technique (via computer generated random number).

\section{Data collection tools and procedures}

Data was collected by using a pretested and structured questionnaire administered by face to face interviews with caregivers by three trained health care providers. The questionnaire was adapted from pediatric AIDS clinical trial group (PACTG) adherence follow up questionnaire. Adherence was measured utilizing the caregivers' report following one month of treatment and the number of times they recalled missing doses. Patients/caregivers who reported an intake of more than $95 \%$ of the prescribed medications were considered to be adherent. Medical charts were reviewed to determine clinical marker of the children.

\section{Data quality assurance}

Data was collected by using a pre-tested questionnaire by trained health care providers. There was continuous supervision to control the data collection procedure. All the data, from each ART site, was checked for completeness, clarity and consistency by the principal investigators and supervisors during the interview day. Data was intensively cleaned before analysis. The reliability of the tool was checked using Cronbach's alpha reliability test with a score of 0.78 (95\% CI $0.76-0.801)$.

\section{Data processing and analysis}

Data was coded and entered in to EPI info version 3.5.3 statistical software and then exported to SPSS Windows 
version 20 for further analysis. Adherence to HAART was assessed by using self reporting methods.

Bivariate logistic regression was used to check variables associated with the dependent variable. Those variables found to have p-values of $\leq 0.2$ were fitted to multivariate logistic regression to control the effects of confounders. Odds ratios with 95\% CI were computed and variables having $\mathrm{p}$-values $\leq 0.05$ in the multiple logistic regression models were considered significantly associated with the dependent variable. Model fitness was checked with the assumptions of Hosmer and Lemeshow goodness of a fit test $(\mathrm{P}=0.79)$.

\section{Ethical considerations}

Ethical clearance was obtained from the Ethical Review Committee of the University of Gondar. Concerned officials at different levels were contacted and permission for the study was secured. Each caregiver/subject was adequately informed about the purpose of the study and written informed consent was obtained from the parents/guardians. Interviews were conducted in private rooms.

\section{Results}

Socio-demographic characteristics of the caregivers and children

A total of 314 child caregivers responded to the structured questionnaire, a response rate of $91.8 \%$. Of the respondents, $230(73.2 \%)$ were females. The mean and the median age of the primary caregivers were 37.77 years \pm 6.05 and 35, respectively. Three hundred and one (59.59\%), were Amhara in ethnicity, 269 (85.7\%) were Orthodox in religion. One hundred and four (33.1\%) were not able to read and/or write. Two hundred and thirty four (74.5\%) of the caregivers had a family size of less than or equal to five. Most of the care givers interviewed 210 (66.9\%) were the biological parents of the children. Of the 314 children, 176 (56.1\%) were males and $54.7 \%$ were age $10-15$ years (Table 1 ).

\section{Clinical marker of the children on ART}

More than half (52.2\%) of the children were WHO stage II classification. Seventy one (22.6\%) of the children had CD4 count of $<200$ cells $/ \mathrm{mm} 3$ at the start of the treatment (Table 2).

\section{Knowledge of caregivers towards ARV Medications}

Of the respondents, 200 (63.7\%), were aware of ART before their child started treatment. For the knowledge assessment questions, 305 (97.1\%) of the respondents knew the types of medication their child was taking and 307 (97.8\%) of them knew that children taking ART would be required to take the medications for the rest of their life to delay AIDS progression.
Table 1 Socio-demographic characteristics of caregivers and children on HAART at Gondar University Hospital and Ploy Clinic April $2012(n=314)$

\begin{tabular}{|c|c|c|c|}
\hline \multicolumn{4}{|c|}{ I) Socio-demographic characteristics of caregivers } \\
\hline \multicolumn{2}{|c|}{ Socio-demographic variables } & \multirow{2}{*}{$\begin{array}{l}\text { Number } \\
(\mathrm{n}=314)\end{array}$} & \multirow{2}{*}{$\begin{array}{l}\text { Percent (\%) } \\
26.8\end{array}$} \\
\hline Sex & Male & & \\
\hline & Female & 230 & 73.2 \\
\hline \multirow[t]{4}{*}{ Age } & $<20$ & 5 & 1.6 \\
\hline & $20-39$ & 210 & 66.9 \\
\hline & $40-59$ & 67 & 21.3 \\
\hline & $>60$ & 32 & 10.2 \\
\hline \multirow[t]{3}{*}{ Ethnicity } & Amhara & 301 & 95.9 \\
\hline & Tigray & 10 & 3.2 \\
\hline & Oromo & 3 & 1.0 \\
\hline \multirow[t]{5}{*}{ Marital status } & Married & 128 & 40.8 \\
\hline & Single & 66 & 21 \\
\hline & Widowed & 66 & 21 \\
\hline & Divorced & 53 & 16.9 \\
\hline & Separated & 1 & 0.3 \\
\hline \multirow[t]{3}{*}{ Educational status } & Illiterate & 104 & 33.1 \\
\hline & Elementary & 146 & 46.5 \\
\hline & Grade $12+$ & 64 & 20.4 \\
\hline \multirow[t]{5}{*}{ Occupational status } & Non employed & 95 & 30.25 \\
\hline & Merchant & 65 & 20.7 \\
\hline & Daily labor & 50 & 15.9 \\
\hline & Farmer & 38 & 12.1 \\
\hline & Civil servant & 62 & 19.7 \\
\hline \multirow[t]{2}{*}{ Monthly income } & $\leq 525$ ETB* $^{*}$ & 189 & 60.2 \\
\hline & $>525 \mathrm{ETB}^{*}$ & 125 & 39.8 \\
\hline \multirow[t]{2}{*}{ Family size } & $\leq 5$ & 234 & 74.5 \\
\hline & $>5$ & 80 & 25.5 \\
\hline
\end{tabular}

\begin{tabular}{|c|c|c|c|}
\hline \multicolumn{4}{|c|}{ II) Socio-demographic characteristics of children } \\
\hline \multicolumn{2}{|c|}{ Socio-demographic variables } & \multirow{2}{*}{$\begin{array}{l}\begin{array}{l}\text { Number } \\
(\mathrm{n}=\mathbf{3 1 4})\end{array} \\
210\end{array}$} & \multirow{2}{*}{\begin{tabular}{|l} 
Percent (\% \\
66.9
\end{tabular}} \\
\hline Type of parent & Biological & & \\
\hline & Relative & 94 & 29.9 \\
\hline & Adoptive & 10 & 3.2 \\
\hline \multirow[t]{2}{*}{ Sex of children } & Male & 176 & 56.1 \\
\hline & Female & 138 & 43.9 \\
\hline \multirow{3}{*}{$\begin{array}{l}\text { Age of children } \\
\text { (in years) }\end{array}$} & $0-4$ & 28 & 8.9 \\
\hline & $5-9$ & 114 & 36.3 \\
\hline & $10-15$ & 172 & 54.7 \\
\hline \multirow[t]{2}{*}{$\begin{array}{l}\text { Educational status } \\
\text { of children }\end{array}$} & $\begin{array}{l}\text { Attending } \\
\text { formal education }\end{array}$ & 206 & 65.6 \\
\hline & $\begin{array}{l}\text { Not attending } \\
\text { formal education }\end{array}$ & 108 & 34.4 \\
\hline
\end{tabular}

*Ethiopian Birr. 


\begin{tabular}{|c|c|c|}
\hline Variables & Number $(n=314)$ & Percent $(\%$ \\
\hline \multicolumn{3}{|c|}{ WHO Clinical stage } \\
\hline Stage I & 56 & 17.8 \\
\hline Stage II & 164 & 52.2 \\
\hline Stage III & 92 & 29.2 \\
\hline Stage IV & 2 & 0.6 \\
\hline \multicolumn{3}{|c|}{ CD4 counts at start of treatment } \\
\hline$<200$ & 71 & 22.6 \\
\hline 200-499 & 164 & 52.2 \\
\hline$\geq 500$ & 79 & 25.2 \\
\hline \multicolumn{3}{|c|}{ Current CD4 count } \\
\hline$<200$ & 52 & 16.5 \\
\hline 200-499 & 138 & 43.9 \\
\hline$\geq 500$ & 124 & 39.5 \\
\hline
\end{tabular}

The summary knowledge questions revealed that 282 (89.2\%) of the respondents had significant knowledge about ART.

\section{Patient provider relationship}

Almost all of the caregivers, 306 (97.5\%), felt they have a good relationship with their health care providers and 303 (96.5\%) also have open communication. Almost all individuals, 310 (98.7\%), reported how helpful the health care providers in the ART unit were in dealing with their medical problems.

\section{Health care system and clinical setting}

All the respondents had access to pharmacies whenever they wanted and were satisfied with the ease of scheduling appointments and confidentiality. Almost all of the respondents, 308 (98.1\%), were satisfied by the changes/improvement their child experienced from the treatment.

\section{Recommended ARV regimen for children}

All children were taking fixed dose combination (FDC) pills. More than half (52\%) had been taking AZTT/3TC/ NVP base regimen and the remaining $28 \%, 12 \%$ and $8 \%$ were under AZT/3TC/EFV, d4T/3TC/NVP and $\mathrm{d} 4 \mathrm{~T} / 3 \mathrm{TC} /$ EFV regimens respectively.

\section{Adherence assessment}

Of the total children taking ART, 182 (57.9\%) of them had a history of missing at least one dose in the last month prior to the survey. Adherence to HAART in HIV positive children during the past three and seven days was assessed and 310 (98.7\%) and 304 (96.8\%) of the children took greater than $95 \%$ of the total prescribed doses respectively. According to the care givers report, the level of adherence to HAART among children was $284(90.4 \%)$ in the one month recall period before the survey. Among the caregivers, $182(57.9 \%)$ of them disclosed their child's sero status to the child.

\section{Reasons for missing ARV drugs}

The common reasons, mentioned by the respondents, for missed doses were forgetfulness 44 (52.3\%), medication fatigue $22(26.2 \%)$, caregiver fear of giving the medication witnessed by other people 12 (14.3.3\%), caregiver illness $10(11.9 \%)$ and others 6 (7.14\%) away from home, transfer related cases, and religious beliefs leading to use of e.g. holy water.

\section{Factors associated with adherence to HAART}

Through multivariate logistic regression; the age of the child $[\mathrm{AOR}=0.37(95 \% \mathrm{CI}: 0.31,0.46)]$, disclosure of the child's HIV status to the child [AOR $=0.27(95 \%$ CI: 0.24 , $0.32)$ ], and caregiver knowledge of ARV medication $[\mathrm{AOR}=4.7(95 \% \mathrm{CI}(3.7,5.6)]$, were independently associated with adherence to ART (Table 3).

\section{Discussion}

Today HIV-infected infants and children survive to adolescence and adulthood, but the issue of adherence is still a great challenge.

The overall HAART adherence among children, who were followed up in Gondar University Hospital and Gondar Poly Clinic, was $90.4 \%$ by self report assessment. The treatment adherence level found in this study was higher in comparison to studies conducted previously in Ethiopia (80.9\%) [13], Nigeria (80\%) [14] and Togo (80\%) [15].

This finding was also higher as compared to studies conducted in Italy and Uganda which revealed the level of adherence ranges from 79\%-90\% [16-18]. This result can be explained because the children were on fully subsidized ART and also had a good patient/provider relationship (97.5\%) with open communication (96.5\%). The other explanation is that most of the children didn't experience any adverse effects of the medication since side effects are known to increase non adherence [19]. However, our findings are almost consistent with a study conducted in New Delhi (91.4\%) [20].

In this study, treatment adherence to ART was significantly associated with the age of the children $(\mathrm{P}<0.01)$. As the age of the child increased the level of adherence to treatment decreased by $63 \%,[\mathrm{AOR}=0.37$ (95\% CI: 0.31 , $0.46)]$ which is inconsistent with other studies conducted in Nigeria, Togo, Italy and Brazil $[8,14,15,21]$. This decrease can be explained by care givers delegating treatment 
Table 3 Factors determining adherence among HIV positive children on at Gondar University Hospital and Ploy Clinic April 2012

\begin{tabular}{|c|c|c|c|c|c|}
\hline Variables & $\begin{array}{l}\text { Adhered } \\
\text { no (\%) }\end{array}$ & $\begin{array}{l}\text { Non adhered } \\
\text { no }(\%)\end{array}$ & $\begin{array}{l}\text { Crude OR } \\
(95 \% \mathrm{Cl}) \\
\end{array}$ & $\begin{array}{l}\text { Adjusted OR } \\
(95 \% \mathrm{Cl})\end{array}$ & P- value \\
\hline \multicolumn{6}{|l|}{ Child age } \\
\hline $0-4$ & $26(8.3 \%)$ & $2(0.64 \%)$ & 1 & 1 & \\
\hline $5-9$ & $108(34.4 \%)$ & $6(1.9 \%)$ & $0.52(0.46,0.67)$ & $0.42(0.36,0.54)$ & 0.01 \\
\hline $10-15$ & $150(47.8 \%)$ & $22(7 \%)$ & $0.52(0.42,0.64)$ & $0.37(0.31,0.46)$ & 0.003 \\
\hline \multicolumn{6}{|c|}{ Educational status of care giver } \\
\hline Illiterate & $92(29.3 \%)$ & $12(3.8 \%)$ & 1 & 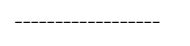 & \\
\hline Elementary & $132(42.0 \%)$ & $14(4.5 \%)$ & $1.2(1.05,1.65)$ & & \\
\hline Secondary and above & $60(19.1 \%)$ & $4(1.27 \%)$ & $0.2(0.15,0.29)$ & & \\
\hline \multicolumn{6}{|l|}{ Disclosure } \\
\hline Yes & $158(50.3 \%)$ & $24(7.6 \%)$ & $0.31(0.25,0.37)$ & $0.27(0.24,0.32)$ & 0.001 \\
\hline No & $126(40.1 \%)$ & $6(1.9 \%)$ & 1 & & \\
\hline \multicolumn{6}{|c|}{ Occupational status of care givers } \\
\hline Non employed & $87(27.7 \%)$ & $8(2.5 \%)$ & 1 & 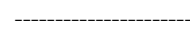 & \\
\hline Employed & 197(62.7\%) & $22(4.7 \%)$ & $0.82(0.61,0.98)$ & & \\
\hline \multicolumn{6}{|c|}{ Knowledge of care giver } \\
\hline Good & $262(83.4 \%)$ & $20(6.4 \%)$ & $5.95(4.2,6.7)$ & $4.7(3.7,5.6)$ & 0.001 \\
\hline Poor & $22(7.0 \%)$ & $10(3.2 \%)$ & 1 & & \\
\hline
\end{tabular}

[Odd ratios (OR) with 95\% Confidence intervals (CI)].

responsibilities to the child irrespective of the child's knowledge of the medications and their importance.

Disclosure is a critical step and has implications for adherence. Starting with disclosure as early as $8-9$ years of age and combining it with specific support is important to increase children's adherence as they get older [16]. However, in our study, the level of adherence was significantly lower $[\mathrm{AOR}=0.27$ (95\% CI: 0.24, 0.32)] in children who were aware of their sero status than in those who unaware of their status $(\mathrm{P}<0.01)$. This finding is in line with other studies $[16,21]$ but inconsistent with studies from Uganda [22] and Democratic Republic of Congo [23]. These studies suggest correlation with professional and ongoing counseling after disease disclosure to children.

The study also showed that caregivers of children with good knowledge about the disease were 4.7 times [AOR = $4.7(95 \%$ CI $(3.7,5.6)]$ more likely to adhere to HAART than their counterparts. This finding is similar to another study conducted in another region of Ethiopia [13,24].

Though our study does not reveal the presence of an association between treatment adherence and type of caregivers, other authors have suggested that children who live in institutions adhere better to treatment than children who live with their biological parents [16]. Foster parents are trained to provide proper care for their adopted children and showed optimal adherence [25]. Health care providers should strengthen adherence counseling during follow up and address proper usage of medication reminders.

\section{Limitation of the study}

This study has some important limitations that should be borne in mind when interpreting the results. Firstly, since the level of adherence was assessed using caregivers self reports, this may have resulted in an overestimation of the adherence level and may also have been prone to recall bias. In addition the data was gathered by interview; therefore there is some potential to social desirability bias. Furthermore, this study did not assess the knowledge of HIV and HAART among the older children and the effect of this knowledge on their adherence. Finally, this study was not triangulated with qualitative methods.

\section{Conclusion}

In this study, the level of adherence to antiretroviral therapy was found to be high. Disclosure of the child's sero status to the child, age of the child and caregivers knowledge of ARV treatment were factors associated with HAART adherence.

\section{Competing interests}

The authors declare that they have no competing interests.

\section{Authors' contributions}

BA carried out the study starting from conception, analysis and interpretation of data and drafted the manuscript. TB participated in data analysis, interpretation and in critical review of the manuscript. AM participated in reviewing, data analysis, commenting on and drafting the manuscript. All authors read and approved the final draft of the manuscript. 
Authors' information

Tadis Brhane Tesfahunegn and Anteneh Messele Birhanu are co-authors.

\section{Acknowledgment}

The author's gratitude goes to the University of Gondar, research and community service core process for providing financial support. We extend our gratitude to study subjects for their participation and willingness to be involved in the interview. We would also like to extend our heartfelt gratitude to Allyson A. Sterman and Sandra Aldridge whom provided us with valuable comments and helped us by editing the language of the manuscript. Last but not least we would like to thank all health care providers who helped with data collection.

Received: 1 October 2013 Accepted: 21 August 2014

Published: 26 August 2014

\section{References}

1. World Health Organization: Changing History. http://www.who.int/whr/2004/] en

2. United Nation Acquired Immunodeficiency Syndrome: World AIDS Facts. Treatment, Prevention and Care. 2011. http://www.unaids.org/globalreport.

3. UNAIDS: AIDS Epidemic Update Global Report. 2007.

4. United Nation Acquired Immunodeficiency Syndrome: HIV Data. Knowledge Centre. 2010. http://www.unaids.org.

5. Federal Ministry Health of Ethiopia: In Single Point HIV Prevalence Estimate. Edited by HIV/AIDS prevention and control office. Addis Ababa, Ethiopia: Federal Ministry Health of Ethiopia; 2007.

6. Federal Ministry of Health: In Accelerated Access to HIV/AIDS Prevention, Care and Treatment in Ethiopia:ROAD MAP 2007-2008. Edited by HIV/AIDS prevention and control office. Ethiopia: Federal Ministry of Health; 2010.

7. Federal Ministry Health of Ethiopia: In Pediatric HIV/AIDS Care and Treatment In Ethiopia, Results of a Situational Analysis. Edited by The International Center for AIDS Care \& Treatment Programs. Ethiopia: Federal Ministry Health of Ethiopia; 2006.

8. World Health Organization: Scaling up Antiretroviral Therapy in ResourceLimited Settingstreatment Guide Lines for Public Health. Geneva, Switzerland: World Health Organization; 2003.

9. Starace F, Massa A, Amico KR, Fisher JD: Adherence to antiretroviral therapy: an empirical test of the information-motivation-behavioral skills model Health psychology. J Division Health Psychol 2006, 25(2):153-162.

10. Federal Ministry of Health: Guidelines for Paediatric HIVIAIDS Care and Treatment in Ethiopia. Ethiopia: Federal Ministry of Health; 2008.

11. Shah A: Adherence to high activity antiretroviral therapy (HAART) in pediatric patients infected with HIV. Issues Interventions 2007, 74(1):55-60.

12. World Health Organization: Antiretroviral Therapy of HIV Infection in Infants and Children Towards Universal Access, Recommendations for a Public Health Approach. Geneva: World Health Organization; 2006.

13. Azmeraw D, Wasie B: Factors associated with adherence to highly active antiretroviral therapy among children in two referral hospitals, Northwest Ethiopia. Ethiop Med J 2012, 50(2):115-124.

14. Mukhtar M, Gwarzo D, Zubaida Farouk Ladan: Preliminary investigation of adherence to antiretroviral therapy among children in Aminu Kano Teaching Hospital. Nigeria African J AIDS Res 2006, 5(2):141-144.

15. Polisset J, Ametonou F, Arrive E, Aho A, Perez F: Correlates of adherence to antiretroviral therapy in HIV-infected children in Lome, Togo, West Africa. AIDS Behav 2009, 13(1):23-32.

16. Giacomet V, Aalbano F, Starace F, De Franciscis A, Giaquinto C, Castelli Gattinara G, Bruzzese E, Gabiano C, Galli L, Vigano A, Caselli D, Guarino A: Adherence to antiretroviral therapy and its determinants in children with human immunodeficiency virus infection: a multicentre, national study in Italy. Acta Paediatr 2003, 92:1398-1420.

17. Nabukeera-Barungi N, Israel K, Alyesubula Addy K, Jayne Byakika T, Philippa M: Adherence to antiretroviral therapy in children attending Mulago Hospital. Kampala Annals Tropical Paediatrics 2007, 27:123-131.

18. Albano F, Giacomet F, Marco G, Bruzzese E, Starace F, Alfredo G: Adherence to antiretroviral therapy in children: A comparative evaluation of caregiver reports and physician judgment. AIDS Care July 2007, 19(6):1764-1766.

19. Malta M, Maya L, Scott C, Fernando F, Francisco I: Adherence to antiretroviral therapy:a qualitative study with physicians from Rio de Janeiro, Brazil, Cad. Saúde Pública Rio de Janeiro 2005, 21(5):1424-1432.
20. Bhattacharya M, Dubey A: Adherence to antiretroviral therapy and its correlates among HIV-infected children at an HIV clinic in New Delhi. Ann Trop Paediatr 2011, 31(4):331-337.

21. Margaret $A$ : Factors affecting adherence to antiretroviral therapy. Clin Infect Dis 2000, 30:S171-S176.

22. Nabukeera-Barungi N, Kalyesubula A, Kekitiinwa A, Byakika-Tusiime J, Musoke P: Adherence to antiretroviral therapy in children attending Mulago Hospital, Kampala. Ann Trop Paediatr 2007, 27(2):123-131.

23. Fetzer BC, Mupenda B, Lusiama J, Kitetele F, Golin C, Behets F: Barriers to and facilitators of adherence to pediatric antiretroviral therapy in a sub-Saharan setting: insights from a qualitative study. AIDS patient Care STDs 2011, 25(10):611-621.

24. Biadgilign S, Deribew A, Amberbir A, Deribe K: Adherence to highly active antiretroviral therapy and its correlates among HIV infected pediatric patients in Ethiopia. BMC Pediatr 2008, 8:53

25. Porto Alegre: Adherence to antiretroviral therapy in children: a study of prevalence and associated factors. N Cad Saúde Pública Rio de Janeiro 2007, 3:\$424-\$434

doi:10.1186/1471-2458-14-875

Cite this article as: Dachew et al:: Adherence to highly active antiretroviral therapy and associated factors among children at the University of Gondar Hospital and Gondar Poly Clinic, Northwest Ethiopia: a cross-sectional institutional based study. BMC Public Health 2014 14:875.

\section{Submit your next manuscript to BioMed Central and take full advantage of:}

- Convenient online submission

- Thorough peer review

- No space constraints or color figure charges

- Immediate publication on acceptance

- Inclusion in PubMed, CAS, Scopus and Google Scholar

- Research which is freely available for redistribution

Submit your manuscript at www.biomedcentral.com/submit
C Biomed Central 